\title{
As Classes Especiais e Helena Antipoff: uma Contribuiçấo à História Da EducaÇáo Especial no Brasil ${ }^{1}$ \\ Special Classes and Helena Antipoff: a Contribution to the History of \\ SPECIAL EDUCATION IN BRAZIL
}

\author{
Adriana Araújo Pereira BORGES²
}

\begin{abstract}
RESUMO: desde 1927 constava no Regulamento do Ensino Primário de Minas Gerais a proposta de homogeneização das classes escolares, mas sua implantação ocorreu somente com a chegada em Belo Horizonte da psicóloga Helena Antipoff. Com a homogeneização das classes, estabelecem-se as classes especiais, presentes na Europa desde o final do século 19. O objetivo é analisar a proposta das classes especiais a partir da análise documental do periódico Infância Excepcional publicado nos boletins da Secretaria da Educação e Saúde Pública do governo de Minas Gerais nos anos de 1930 e 1940 e de outros artigos publicados sobre o tema. Busca-se verificar como as classes especiais foram sistematizadas no contexto brasileiro, a partir das orientaçóes de Helena Antipoff. Ela nasceu na Rússia, morou na França e estagiou no laboratório de Binet, antes de seguir para Genebra, onde finalizou seus estudos no Instituto Jean Jacques Rousseau. A hipótese é que a formaçâo multicultural de Helena Antipoff influenciou a maneira como as classes especiais se configuraram em Minas Gerais e, posteriormente, no Brasil, contribuindo para o tratamento e a educação das crianças deficientes no país. As classes especiais mineiras, principalmente as do Instituto Pestalozzi, constituíram-se como locais de aplicação de uma metodologia diferenciada. A atual historiografia da ciência tem evidenciado que o conhecimento tem que se tornar local para funcionar como conhecimento. Embora profundamente marcada pela trajetória na Europa, é somente a partir do conhecimento do contexto cultural mineiro e de suas especificidades que Antipoff pode reafirmar a importância do conceito de Inteligência Civilizada.
\end{abstract}

PALAVRAS-CHAVE: Educação Especial. Helena Antipoff. Classe Especial.

\begin{abstract}
Since 1927 the proposal of homogenization of school classes was included in the Regulation of Primary School of Minas Gerais, but its implementation only occurred with the arrival in Belo Horizonte of the psychologist Helena Antipoff. With the homogenization of the classes, special classes, existing in Europe since the end of the nineteenth century, were established. The objective is to analyze the special classes proposal using documentary analysis of the journal Infancia Excepcional (Exceptional Childhood) edited in the bulletins of the Minas Gerais Board of Education and Public Health during the years 1930s and 1940s, along with other articles published on the subject. This article seeks to verify how the special classes were systematized in the Brazilian context under Helena Antipoff's supervision. Born in Russia, she lived in France where she did her internship in Binet's laboratory before moving to Geneva where she finished her studies at the Jean Jacques Rousseau Institute. The hypothesis is that Helena Antipoff's multicultural formation influenced how the special classes were set up in Minas Gerais and, subsequently, in Brazil, contributing to the treatment and education of disabled children in the country. The Minas Gerais special classes, mainly the ones at the Pestalozzi Institute, constituted places for applying a careful methodology. Current historiography of science has shown that knowledge must become local to function as knowledge. Although profoundly marked by her European trajectory, it is only through the knowledge of the Minas Gerais context and its specificities that Antipoff was able to reaffirm the importance of the concept of Civilized Intelligence.
\end{abstract}

KEYWORDS: Special Education. Helena Antipoff. Special Classes.

\section{INTRODUÇÃ́O}

Em 1929, chega a Belo Horizonte, a psicóloga Helena Antipoff (1892-1974). Formada no Instituto Jean - Jacques Rousseau (IJJR), um importante centro de estudos em ciências da educação, situado em Genebra, na Suíça, Helena Antipoff atuou também com crianças órfãs na Rússia na época da revolução comunista.

\footnotetext{
${ }^{1}$ http://dx.doi.org/10.1590/S1413-65382115000300003

${ }^{2}$ Pós-doutoranda em Educação, Universidade Federal de Minas Gerais, Belo Horizonte, MG, Brasil. adriana.borges@terra.com.br
} 
Ela teve uma educação cuidadosa na Rússia, seu país natal, antes de embarcar aos 17 anos para Paris, onde pretendia formar-se em medicina. Passou a frequentar aulas de psicologia na Sorbonne e aos poucos, o interesse por essa ciência aumentou. Procurou então, um estágio no Laboratório de Alfred Binet e Theodore Simon, localizado na Rue Grange-aux-Belles. Binet acabara de falecer, o ano era 1911 e Simon a aceitou como estagiária. De acordo com Campos (2010), o laboratório foi criado em 1904 para que os pesquisadores orientados por Alfred Binet, pudessem ter acesso aos escolares nos quais pretendiam testar a escala métrica de inteligência. Na mesma rua do Laboratório havia uma escola primária e seu diretor permitiu que as crianças fossem avaliadas. A primeira escala, conhecida como "Escala Binet-Simon" foi apresentada em 1905.

É nesse laboratório que a jovem Antipoff conhece o psicólogo suíço Édouard Claparède (1873-1940), que a convida para fazer parte da primeira turma do recém criado Instituto JeanJacques Rousseau. Em Genebra, além de aluna da primeira turma do IJJR em 1912, foi professora a partir de 1927, além de assistente de laboratório de Édouard Claparède. Essa experiência permitiu a consolidação de sua perspectiva teórica. Conviveu com Claparède, considerado como um dos grandes nomes da psicologia da educação, estabelecendo uma relação próxima de trabalho e pessoal, como demonstrado na correspondência publicada entre os dois (RUCHAT, 2010). A formação no IJJR, humanista por excelência, foi assimilada por Antipoff.

No Instituto, havia a preocupação com os direitos da criança. Os ideais da Escola Nova eram discutidos e aplicados na Maison des Petits, a escola anexa ao Instituto onde Antipoff também estagiou. Nessa perspectiva, a criança é o centro do processo educativo e não o professor. Ela é quem conduz o processo de aprendizagem. Havia também, uma preocupação com a educação pela paz, pois a primeira grande guerra mundial impactou fortemente alunos e professores do Instituto. Helena Antipoff formou-se, portanto, numa instituição que prezava o respeito às diferenças individuais.

Ela ainda conviveu com outros nomes importantes da psicologia genebrina, como Alice Descoeudres (1877-1963), por quem tinha grande admiração. Alice Descoeudres foi professora no IJJ. Por vinte e cinco anos, Alice Descoeudres lecionou também na École de Malagnou, em Genebra, para crianças especiais. Antes de assumir a classe, Descoeudres passou quatro meses em Bruxelas, na Bélgica, com Decroly, onde observou as classes especiais e aprendeu sobre o método de ensino para as crianças com deficiência. Ela também trabalhou na adaptação dos testes de Binet, já que o programa escolar era diferente do programa escolar francês, adequando as perguntas ao contexto local. Para Cleopazzo (1996), Descouedres dedicou-se a três domínios: a escola ativa, a psicologia experimental e a educação moral, mas esses três domínios atados a uma causa muito maior, a educação das crianças "retardadas". Ou seja, Descoeudres, nunca abandonou as crianças pelas quais dedicou toda a sua vida, aliando a pesquisa com a prática na classe especial. Escreveu vários livros e publicou diversas pesquisas, mas seu livro mais importante foi "A Educação das Crianças Retardadas", publicado em sete idiomas. No Brasil, o livro foi editado pela SPMG, após Descoeudres ceder os direitos autorais para Antipoff. Em 1916, Antipoff saiu de Genebra em direção à Rússia. A revolução estava prestes a eclodir e seu pai necessitava de auxílio. Devido à revolução, foi impedida de sair do país por oito anos. Nesse período, trabalhou com crianças abandonadas em abrigos abertos pelo governo comunista. Trabalhou também em consultório médico pedagógico na cidade 
de Viatka. Nesse período, tomou conhecimento do trabalho de um psicólogo russo chamado Lazurski. O método empregado por ele, chamado de Experimentação Natural, pretendia traçar um perfil caracterológico da criança em seu ambiente natural. Essa técnica, aprendida na Rússia, também foi aplicada nas crianças do Instituto Pestalozzi de Minas Gerais.

Em 1929, foi convidada pelo governo mineiro para assumir as aulas de Psicologia da Educaçãoo e Psicologia Experimental da Escola de Aperfeiçoamento de Professores de Belo Horizonte, bem como seu laboratório de psicologia. A Escola formava professoras já atuantes, tanto na capital quanto no interior de Minas Gerais, além de receber alunas de outros estados. Trabalha também na homogeneização das classes escolares, prevista desde 1927 pelo Regulamento do Ensino Primário.

Sua atuação no processo de homogeneização de classes consistia em treinar as professoras para avaliar as crianças através da aplicação de testes de inteligência. O Laboratório também ficou encarregado da classificação das crianças das escolas do interior do estado. Com base nos testes, as crianças seriam encaminhadas para classes divididas de acordo com os resultados obtidos. A homogeneização das classes começou a produzir o que Fazzi (2005) nomeou como efeitos colaterais. Os professores dispunham de poucos recursos para lidar com as crianças que se mostravam abaixo da média de inteligência. Foi necessário buscar novos espaços de atuação onde Antipoff tivesse maior autonomia para desenvolver seu trabalho.

$\mathrm{O}$ interesse de Antipoff pelas crianças anormais ${ }^{3}$ foi crescendo à medida em que o trabalho nas classes especiais exigia mais recursos pedagógicos, psicológicos, médicos, enfim, recursos de toda ordem. Como pesquisadora, a pergunta que se colocava era: como educar os anormais?

Eu não sei se já lhe escrevi, que o estudo dos anormais me parece de uma tal importância e de tal interesse que estou em vias de me especializar. Em minha estadia na Europa, depois nos Estados Unidos, vou tentar precisamente usar para visitar estabelecimentos e seguir cursos sobre o assunto. Eu tenho a impressão que retiramos do estudo e da educação dos anormais para o conhecimento da personalidade normal e sua pedagogia pouca coisa, sobretudo no domínio da afetividade e das tendências instintivas. Ora, a conduta dos débeis mentais suscitam problemas de alto valor para a compreensáo dos mecanismos normais que resolvê-los é dar um enorme passo adiante na direçáo das crianças dotadas acima do normal, justamente aquelas que sáo mal educadas e que causam tanto mal quando adultas (RUCHAT, 2010, p.165, tradução nossa).

A Sociedade Pestalozzi surge, portanto, num momento de convergência das necessidades pessoais de Helena Antipoff, disposta a ampliar seu trabalho de assistência à criança anormal, com as necessidades da sociedade mineira. Reúne então, um grupo de intelectuais bastante influentes na sociedade da época e propóe a criação de uma associação que pudesse se dedicar aos cuidados, educação e tratamento das crianças anormais. Essa associação recebeu o nome de Sociedade Pestalozzi de Minas Gerais (SPMG).

A SPMG foi criada no mês foi novembro de 1932 e o Laboratório de Psicologia da Escola de Aperfeiçoamento foi, durante algum tempo, seu endereço. Ato de um grupo organizado, mas com a centralidade do nome de Helena Antipoff, a sociedade foi presidida por ela de 1932 até 1945.

\footnotetext{
${ }^{3}$ Anormais era o termo utilizado na década de 1930 para se referir às crianças com deficiências motoras, intelectuais, sensoriais e que apresentavam problemas de comportamento.
} 
A primeira iniciativa da SPMG, em 1932, foi o auxílio às classes especiais. Professoras em formação na Escola de Aperfeiçoamento visitavam as classes especiais e além de levar materiais para utilização em sala de aula, orientavam as aulas. A segunda iniciativa foi a abertura do consultório médico pedagógico em 1933. A princípio, os médicos abriam horários em suas agendas para atender as crianças. $\mathrm{O}$ consultório foi um importante centro de triagens para as classes especiais, além de oferecer o tratamento e acompanhamento para as crianças. Em 1934, é inaugurada a Casa do Pequeno Jornaleiro, outra importante iniciativa. Nela, crianças vendedoras de jornal da capital mineira e outras crianças trabalhadoras, podiam dormir, tomar banho, descansar e aprender ofícios. Por fim, o Instituto Pestalozzi, criado em 1935. O Instituto abarcou o consultório médico pedagógico, que passou a ter um médico responsável. Estruturou-se como uma escola especial, onde dava-se atenção também a aprendizagem de ofícios. Embora as diretrizes de funcionamento das classes especiais das escolas mineiras e do Instituto Pestalozzi, como proposto por Antipoff fosse o mesmo, no Instituto a proximidade com as crianças era maior. A própria Antipoff atendia crianças no consultório médico pedagógico, realizava triagens e propunha formas inovadoras de intervenção.

A hipótese é de que as classes especiais implantadas em Belo Horizonte constituíram-se como um importante exemplo da circulação do conhecimento e de como uma cultura absorve e transforma conceitos. Como afirma Campos (2002), a atividade científica tornou-se passaporte para muitos indivíduos que passaram pela experiência da mudança de cultura, muito comum durante a primeira metade do século XX, nos momentos em que as crises sociais europeias se sucederam.

Em sua trajetória particular - mas ao mesmo tempo com essa dimensão universal, já que se trata
de experiência de vida compartilhada por muitos outros intelectuais de seu tempo -, pode-se
observar esse duplo movimento que animou a vida desses pioneiros: por um lado, a procura de
uma linguagem universal que lhes permitisse a leitura da realidade em diferentes contextos -
procura essa, de resto, constitutiva da própria atividade científica -, por outro, a busca de uma
identidade que tornasse possível a adaptação ao ambiente estranho. Ambos os movimentos
podem ter levado, em casos como o de Antipoff, a sínteses adaptativas bem-sucedidas (CAM-
POS, 2002, p. 30).

Nesse sentido, é fundamental o conceito de inteligência civilizada criado por Antipoff. As práticas sugeridas para as classes especiais, inspiradas na obra de Descoeudres e na Ortopedia Mental de Binet, sustentam-se na concepção de que as crianças anormais podem aprender. Ainda de acordo com Campos (2002), podemos afirmar que histórias como a de Helena Antipoff ajudam a compreender a história da ciência e da educação nas Américas.

\section{FONTES}

Para a realização desta pesquisa foram utilizados tanto os documentos preservados na Sala Helena Antipoff, localizada na Biblioteca Central da UFMG, quanto os arquivados do Centro de Documentação e Pesquisa Helena Antipoff (CDPHA/UFMG), em Ibirité, MG. Dentro do acervo, alguns registros são fundamentais. É possível destacar a importância dos Boletins, publicações da Secretaria de Educação e Saúde Pública de Minas Gerais, principalmente três desses, chamados de Infância Excepcional, de números 12, 16 e 20; datados de 
1933, 1934 e 1937, respectivamente. Nessas publicações é possível encontrar artigos dos sócios da Pestalozzi, relatos de atendimentos, fichas de avaliação, enfim, um material muito rico em informaçóes. É preciso considerar que:

Desse modo, ocorre que o conteúdo das fontes históricas apresenta-se sob tipos diversos de organizaçáo: 1) um, referente aos fatores internos (que responde a pergunta: o que era possível pensar e escrever numa dada época?); 2) outro, referente às práticas que expressam um certo tipo de saber. Seguindo este enfoque, podemos definir o domínio da história dos saberes psicológicos como o âmbito do que era possível pensar e escrever sobre o psicológico numa época determinada e também o âmbito das práticas que expressavam um determinado saber (MASSIMI, 2009, p.18).

Esses dois pontos são fundamentais na realização da presente pesquisa. A partir dos documentos, contextualizar a educação nas classes especiais. Samara e Tupy (2007) propóem que o contato com o texto escrito deve suscitar no pesquisador algumas questóes essenciais para uma primeira aproximação. É preciso estar atento à forma que o material se apresenta, o conteúdo que traz e os objetivos e propósitos de quem o elaborou, assim como de quem o lê e interpreta. De acordo com Lopes e Galvão (2005), não existem métodos infalíveis e cada pesquisador deve "inventar" o seu. O importante é que não se faça uma mera descrição do que foi encontrado, mas que o pesquisador possa dar inteligibilidade ao material. Propóe-se então, um novo olhar sobre as classes especiais: um olhar contextualizado, sustentado na pesquisa em fontes primárias, permitindo assim, demonstrar que as classes especiais foram inovadoras na época.

\section{As CLASSES ESPECIAIS EM MiNAS GERAIS E O CONCEITO DE INTELIGÊNCIA CIVILIZADA}

As classes especiais não surgiram aqui no Brasil. Essa proposta já estava sendo implementada em países da Europa, a partir do desafio da obrigatoriedade do ensino primário. A diversidade de crianças que chegaram à escola impulsionou os pesquisadores e técnicos da área da Educação a proporem alternativas para o ensino das crianças que não conseguiam acompanhar a turma na qual deveriam estar inseridas. A classe especial pareceu adequada na época por efetuar uma ideia pedagógica que começava a ganhar força, a ideia de adaptar os métodos pedagógicos às aptidóes da criança e homogeneizar as classes.

Em 1931 iniciam-se os trabalhos de aplicação dos testes nas escolas de Belo Horizonte. A divisão de classes foi feita a partir da aplicação de dois testes: o de inteligência e vocabulário do Dr. Simon para os novatos e o de Dearborn para os repetentes. As classes foram divididas em A, para as crianças consideradas fortes; B, para as médias; C, para as fracas e D, para as anormais (ANTIPOFF, 1932).

Uma das sugestões de organização das classes por Antipoff foi a formação de duas classes de primeiro ano escolar, uma de novatos e outra de repetentes. Para Antipoff, seria muito maçante para uma criança repetente ter que ver novamente os mesmos conteúdos do ano anterior. Para ela:

O aluno repetente sob o ponto de vista psicológico e da técnica escolar, nunca é semelhante àquele que veio à escola a primeira vez. $\mathrm{O}$ repetente, se não progrediu a ponto de atingir a classe superior, acha-se, contudo, em relação aos novatos, com uma superioridade de um terço, um meio ou três quartos do primeiro ano. É, pois, obriga-lo a perder absolutamente o tempo, 
matar-lhe o gosto e alegria, se o fizermos assentar-se junto aos novatos. Ele não tem necessidade de recomeçar sua instrução mas de continuá-la. (ANTIPOFF, 1930/1992b, p.40).

Da criança com o chamado retardo pedagógico, até a criança nomeada como anormal, haveria uma gradação que definiria o lugar adequado para cada uma. Os critérios utilizados na divisão das classes eram a idade real e o quociente intelectual. Sugere ainda a criação da Classe E, para as crianças “[...] difíceis de educar - os agitados, os neuróticos, os anti-sociais, as crianças moralmente defeituosas" (ANTIPOFF, 1930/1992b, p.42). Essas classes receberiam as crianças de inteligência normal, mas cujos problemas comportamentais impedissem o aproveitamento nas classes comuns.

Em correspondência para Claparède (RUCHAT, 2010), Antipoff comunica que desde junho de 1932 passou a funcionar uma classe para anormais, anexa ao Laboratório de Psicologia, para 15 crianças de temperamento apático com deficiência mental. Segundo ela, as crianças seriam submetidas a um regime médico e pedagógico bem restrito,o qual seria observada a influência mútua entre o físico e o mental e vice-versa. A classe foi nomeada como Classe Descouedres. A classe, que ficou sob responsabilidade de Naytres Rezende, funcionou por seis meses.

Também em 1933, foi aberta uma classe anexa à Escola de Aperfeiçoamento que recebeu durante três vezes por semana, cinco crianças "surdo-mudas". Esther Assumpção (1934) fala em oito crianças. Foi ela a professora que ficou encarregada dessa turma. Em 1933, já havia em Belo Horizonte, em 15 grupos escolares, 34 classes especiais. Num total de 9.272 crianças, 883 crianças frequentavam classes especiais, ou seja, 9,5\% da população (SOCIEDADE PESTALOZZI, 1933). As classes foram estabelecidas pelas professoras formadas pela Escola de Aperfeiçoamento, de acordo com os resultados dos testes e observação das crianças (Teste Prime, Teste B. Hor., observação das diretoras e professoras). Outro critério era a repetência. Ou seja, a criança que já havia repetido de ano, provavelmente seria integrada numa classe especial.

A partir de maio de 1933, a professora Naytres Rezende, auxiliar do Laboratório de Psicologia da Escola de Aperfeiçoamento, iniciou um trabalho de orientação e auxilio material às Classes D. Durante um mês, ela visitou cinco grupos escolares e trabalhou em oito classes de primeiro ano. Seu trabalho consistia em visitar os grupos e conhecer as condiçóes físicas, número de alunos e grau de desenvolvimento destes através dos testes Deaborn e Binet Stanford. Ela também dava aulas de ortopedia mental, ginástica e canto. Além disso, deixava uma série de exercícios com a professora para que utilizasse durante a semana com as crianças. Todas as quintas pela manhã, realizavam-se reunióes com as professoras das Classes D, para orientação. As reunióes aconteciam no Laboratório de Psicologia da Escola de Aperfeiçoamento. Nessas ocasióes, eram transmitidos conhecimentos sobre os exercícios de ortopedia mental e repassados materiais cedidos pela Sociedade Pestalozzi (REZENDE, 1933).

Das 34 classes, a média de professoras que compareciam a reunião no Laboratório da Escola de Aperfeiçoamento era de 17 professoras. Cada professora que fosse bem avaliada nos seus trabalhos receberia uma quantidade de dinheiro da Sociedade Pestalozzi, como prêmio, e assim poderia adquirir mais material para sua sala. 
O primeiro relatório sobre esse trabalho de orientação às classes especiais traz um dado que chamou a atenção da professora Naytres: 23,67 \% das crianças foram consideradas normais pela reavaliação feita através de inquéritos sobre defeitos físicos, doenças, defeitos de caráter manifestados pela conduta escolar. Muitos foram encaminhados ao Consultório Médico Pedagógico para exames clínicos e outros exames mentais, realizados através de testes de inteligência como o Deaborn, o Binet- Terman e o Goodenough.

A justificativa de Naytres para um número tão elevado de crianças normais nas classes especiais foi a seguinte: a homogeneização não ocorreu de forma perfeita, pois além das crianças débeis, as classes tinham crianças com problemas de ordem moral, de conduta ou de caráter, que não se desenvolviam nas classes ordinárias. Além disso, as classes especiais recebiam as crianças novatas ou aquelas que "sobravam", ou seja, aquelas que não se encaixavam nas classes da escola e aguardavam até que pudessem ser colocadas em seus devidos lugares.

Convém lembrar, ainda, que o título “Classes D” significava apenas o grau de inferioridade da classe em relação às outras de $1^{\circ}$ ano do mesmo grupo. Assim, poderiam ser de nível mental muito diferente, de acordo com o meio social e com as diversas zonas da cidade (REZENDE, 1934, p.58).

Para Antipoff, "[...] não é a homogeneidade dos alunos que determina o seu sucesso, mas é, cremos nós, o ensino correspondendo ao desenvolvimento das crianças" (ANTIPOFF,1934/1992b, p.27). Resultados escolares, idade e o nível de desenvolvimento mental seriam os critérios utilizados para homogeneizar as classes em Belo Horizonte. Quanto à proposta de divisão das classes pelo QI, Antipoff faz uma ressalva importante, um ponto fundamental na sua obra e muitas vezes negligenciado ou mal interpretado por alguns autores. Trata-se do conceito de inteligência civilizada:

Há muito tempo já, sustentamos a ideia de que a inteligência natural para a grande maioria das crianças, tirante as excepcionalmente dotadas e as excepcionalmente desprovidas sob esse aspecto, é um conceito irreal e confusamente artificial. Já alhures escrevemos que a capacidade de resolver a maior parte dos testes chamados de inteligência geral, é menos uma inteligência natural do que uma inteligência civilizada. Mostramos que os testes de inteligência geral atuais diferenciam de um modo considerável as influências de ordem social - o meio, o ambiente e a educação - a que foram as crianças submetidas, desde o berço, durante a sua vida pré-escolar (ANTIPOFF, 1930/1992b, p. 43).

Para Helena Antipoff, os testes medem a inteligência que foi favorecida por um meio letrado e não que crianças nascidas em meio social elevado sejam mais inteligentes. A inteligência natural é um conceito irreal e confusamente artificial. Ou seja, os testes não medem a capacidade natural, a inteligência real da criança. Por isso, crianças nascidas em meio social privilegiado atingiam escores maiores do que as crianças de meio social desfavorecido. Essa conclusão de Helena Antipoff não foi retirada do acaso. Desde a época em que trabalhou nas Estações Médico-Pedagógicas na Rússia que lhe chamava a atenção o fato de muitas crianças terem resultados pífios em testes, no entanto, demonstrarem ser inteligentes na luta pela sobrevivência:

À margem da família, da escola e da sociedade com suas leis e suas regras, essas crianças se formavam, em uma palavra, à margem da vida civilizada. Não sendo destituídas de inteligência natural, náo possuíam precisamente essa inteligência que se tributa e se disciplina ao contato do exemplo no seio do regime regrado e das exigências impostas pela vida convencional da família 
ou da escola, essa inteligência civilizada, que perscrutamos por meio dos nossos testes chamados de inteligência geral (ANTIPOFF, 1931/2002, p. 86).

Para comprovar essa tese, ela empreendeu um estudo no Laboratório da Escola de Aperfeiçoamento, relacionando inteligência e meio social. Aplicou o teste de inteligência e o de vocabulário do Dr. Simon em mais de mil crianças de sete anos e confrontou o resultado com a profissão dos pais. As profissóes foram agrupadas em quatro categorias, das profissóes liberais cujos pais possuíam ensino superior como engenharia, magistratura, medicina, etc, até os trabalhadores manuais, lavadeiras, mendigos. O resultado foi que as crianças cujos pais possuíam ensino superior atingiram 120 de QI, 100 de QI para a categoria mais numerosa cujos pais seriam operários e artífices, e 90 para as crianças cujos pais pertenciam ao degrau mais baixo da escala de trabalho. A diferença em termo de idade mental da média mais alta de QI encontrada até a média mais baixa apresentava uma diferença de três anos. Ela então conclui que:

Sendo mais poderoso o índice social (aí está uma verdade de grupo, mas não individual, entenda-se bem), somos, pois, obrigados a reconhecer que a seleçáo das crianças na sua entrada para a escola primária pública obedece, para a maioria delas, menos à diferença de desenvolvimento mental sui generis e a dispersão das disposiçôes inatas, do que a variação do grau de civilização que caracteriza cada grupo social de meio familiar da criança (ANTIPOFF, 1930/1992b, p. 44).

Helena Antipoff defendia o uso dos testes, pois depois da criança estar na escola, “[...] as diferenças intelectuais dependentes do meio tendem mais e mais a nivelar-se no decorrer dos anos escolares" (ANTIPOFF, 1930/1992b, p. 44). Assim, os testes serviriam para essa primeira seleção, mas caberia aos professores no decorrer dos anos seguintes a realização de avaliações para a promoção das crianças. Essa seleção seria, portanto, provisória.

[...] Não nos deixemos iludir, porém, com os resultados dos testes mentais. Os melhores dentre eles nunca dão diagnósticos inteiramente exatos e precisos sobre o desenvolvimento espiritual da criança (ANTIPOFF,1930/1992b, p. 33).

Esperemos, pois, dos testes, que se aperfeiçoem sensivelmente uma melhoria tanto no ponto de vista do diagnóstico das aptidóes como do prognóstico para o progresso escolar; esperemos também que os testes escolares e psicológicos aplicados periodicamente nos deem meios preciosos para a medida do trabalho pedagógico, mas não esqueçamos também de registrar, por observaçóes metódicas, os progressos espirituais, sociais e morais que cada criança na escola renovada é chamada a realizar (ANTIPOFF, 1930/1992b, p. 56).

A inteligência era entendida por Antipoff como uma função possível de se desenvolver e não uma função estática. Seria importante organizar baterias de testes apropriados e que estes fossem aplicados periodicamente, para a melhoria do trabalho educativo, coletivo e individual. Os testes auxiliavam na classificação das crianças para a homogeneização das classes, mas serviam também como uma medida para avaliar se as crianças estavam se desenvolvendo. Para Antipoff, Binet era um otimista, que acreditava no desenvolvimento das funçóes e do pensamento.

A seleção das crianças era fundamental para o êxito da empreitada, bem como a seleção dos professores. Para as classes dos bem-dotados, os professores deveriam ser inteligentes e competentes para desempenhar bem seu trabalho. Para as classes dos "retardados e instáveis", 
seria imprescindível a competência pedagógica aliada às virtudes do caráter, como a afeição às crianças, o espírito altruísta, a paciência a abnegação, a busca de meios para tornar eficiente a educação das crianças.

Quanto ao programa, seria o mesmo, mas cada classe executaria em tempos diferentes. $\mathrm{O}$ fato de que no Brasil a escola funcione em meio período somente, dificultaria às crianças da Classe B, por exemplo, a aquisição de todas as competências em um ano somente. A ideia de Antipoff era de que a Classe A pudesse finalizar o programa em um ano, enquanto a Classe B necessitasse de um ano e meio, a Classe $\mathrm{C}$ de dois anos, em média. A flexibilidade no tempo de estudo já estava presente na obra de Antipoff. Nesse sentido, afirma ela, seria muito importante a mudança de concepção das Secretarias de Ensino, que tendem a julgar a competência dos professores pelo número de alunos promovidos no fim do ano escolar.

Quanto à organização das classes, Antipoff também sugeria formar Classes D e E em escolas próximas, constituindo assim, Classes D para deficientes sensoriais numa escola, outra Classe D para deficientes motores em outra, para que o professor pudesse ter uma clientela mais homogênea e programar suas aulas de acordo com as possibilidades e dificuldades de sua turma. O número de crianças também seria variável. Enquanto nas Classes A, a tolerância seria de 40 alunos, nas Classes E esse número não deveria ser superior a 15 alunos.

Embora as classes homogêneas facilitassem o trabalho do professor, Antipoff afirma que não haveria aí um sentido maquiavélico baseado no "dividir para reinar", mas sim "dividir para fortalecer". Ela realmente acreditava que todas as crianças tinham direito ao ensino: “[...] todas sem exceção, pois, que são educáveis, devem ser auxiliadas para se erguerem mais alto, sempre mais alto, na sua ascensão para o aperfeiçoamento intelectual, social e moral" (ANTIPOFF, 1930/1992b, p. 53).

\section{A Metodologia das Classes esPeCiaIs}

O trabalho pedagógico nas classes especiais deveria ser assegurado, primeiramente, pelo interesse no indivíduo e o estágio dos professores nas classes especiais, seria importante para educar nos mestres uma atitude psicológica. Depois, o segundo passo seria desenvolver um trabalho experimental para achar o método pedagógico mais eficaz. O método não seria o mesmo para todas as crianças, mas cada caso deveria ser analisado e encontrado o método mais eficaz. Todos os professores deveriam passar pela experiência da classe especial. Nela deveriam permanecer os que realmente tivessem interesse pelos anormais. Mas todos fariam na classe especial, o estágio indispensável da "escola sob medida", adquirindo o manejo do método experimental, sem o qual, o trabalho pedagógico não passaria de rotina. A metodologia, nas classes especiais, deveria seguir os cinco princípios diretores propostos por Descouedres:

1. A atividade própria do aluno - Agir por si mesma e achar por si mesma, ou seja, a criança deveria agir, manualmente, intelectualmente e corporalmente, esse seria o meio de desenvolver as crianças. Trata-se não de deixar a criança livre, mas de criar oportunidades para a ação. Não se deve exigir uma disciplina rígida, mas oferecer um ambiente adequado para atividades variadas. Deveriam excursionar pela cidade, aproveitar os jardins e pátios. 
2. Educação sensorial - As crianças das classes especiais devem aprender a utilizar melhor seus sentidos, pois muitas vezes olham mas não vêem, escutam mas não ouvem convenientemente.

3. Concentração - deveria ser estimulada a partir dos interesses da criança em assuntos concretos.

4. Individualização do ensino - $\mathrm{O}$ ensino deve ser planejado para criança, de modo a satisfazer suas necessidades físicas e mentais.

5. Caráter utilitário do ensino: Visa um fim social, preparar a criança para a vida, descobrindo em cada criança suas aptidóes, desenvolvê-las e orientá-las para as aplicaçóes práticas.

A educação nas classes especiais, para Antipoff, obedeceria aos princípios da escola moderna para as crianças normais. Antipoff, aqui, refere-se ao fato de que, para ela, a educação especial é a educação ativa:

A atividade livre e variada, o ensino sob medida, os centros de interesse, a preparação para a vida, - tudo isto faz parte do A B C da pedagogia geral. Quanto ao ensino intuitivo e à educaçáo dos sentidos, eles formam a base do trabalho nos jardins da infância (ANTIPOFF, 1931, p. 29).

Para educar as crianças, no sentido funcional dessa palavra, os recursos fundamentais da educação são os mesmos. São nos princípios da escola ativa que se encontram as diretrizes necessárias para educar crianças normais ou de classes especiais. Assim, se os princípios diretores são os mesmos, o que muda é a proporção do que é ensinado nas classes comuns e classes especiais.

Essa proporção deve ser pensada de acordo com a condição de cada classe. Seria necessário preparar as faculdades intelectuais da criança para que ela possa receber o ensino formal. Nas classes especiais a parte educativa deve primar sobre o ensino, ou seja, antes de ler e escrever, o importante é o trabalho de socialização, o trabalho manual e a cultura física. Havia, assim, um objetivo bastante prático nas atividades da Sociedade Pestalozzi, a adaptação do sujeito ao meio. E, além disso, a formulação de uma pedagogia que pudesse atender a diversidade. Em 1934, Antipoff relata sobre o ensino diferenciado nas classes especiais:

Há quase três anos, as classes para crianças retardadas, orientadas pelo Laboratório de Psicologia, têm adotado, ao lado dos processos escolares comuns, alguns processos especiais e um horário próprio, consagrando muito mais tempo, em particular, ao trabalho manual, à de ginástica, ao canto e aos exercícios ortopedia mental (ANTIPOFF, 1934/1992b, p. 28).

Havia, portanto, uma forma de ensinar diferenciada para as crianças das classes especiais, mas os princípios da escola ativa, os fundamentos dessa educação, eram os mesmos. O currículo comum era seguido ao lado de uma pedagogia diferenciada que privilegiava o trabalho manual, a consciência corporal através da ginástica e o canto, pois a noção de ritmo também servia como canal para os outros aprendizados. E nesse contexto, a ortopedia mental foi o método amplamente utilizado nas classes especiais. 


\section{A ORTOPEDia MENTAL}

A ortopedia mental foi criada em 1910 por Alfred Binet. A finalidade dos exercícios de ortopedia mental seria "[...] endireitar, adestrar e fortificar as faculdades mentais" (ANTIPOFF, 1930/1992b, p.67), numa analogia a ortopedia, que tenta corrigir as deformidades do corpo. O treinamento sistemático e repetitivo das funçóes mentais é a base dos exercícios de ortopedia mental, cujo objetivo é a melhora das funçôes mentais. Binet parte do princípio de que, se um músculo pode melhorar sua função através dos exercícios, por que não as funções mentais? A educação talvez não pudesse criar ou aumentar o potencial das faculdades mentais, mas poderia organizá-las, criando na criança condições de aproveitá-las melhor.

A ortopedia mental se caracteriza como uma "[...] ginástica psicológica cujos exercícios, variados e repetidos, vão pôr as faculdades em forma, adestrá-las, uma por uma, tonificá-las e endireitá-las, se preciso" (ANTIPOFF, 1930/1992b, p. 69). Os órgãos dos sentidos seriam exercitados. Os exercícios tinham como finalidade melhorar a percepção das crianças. Partia-se do princípio de que as crianças anormais utilizam o aparelho sensório de forma pouco eficaz comprometendo sua percepção. Os exercícios visavam aprimorar os sentidos, melhorando a percepção. Esses exercícios eram preparados na Escola de Aperfeiçoamento e repassados para as professoras das classes especiais. Como a ortopedia pretendia corrigir as deformidades do corpo, a ortopedia mental pretendia estimular a inteligência. Para isso, seria necessário treinar as funçóes mentais.

De acordo com Antipoff (1931), a aplicação dos exercícios de ortopedia mental nas classes especiais já estava proposta no Regulamento da Instrução Primária Oficial. O Decreto 7.970 - A, de 15 de outubro de 1927, traz em seu Capítulo II, Das classes para retardados pedagógicos, no artigo 380, o seguinte:

Os programas constarão de uma parte relativa á instrucção, compreendendo linguagem escripta e oral, calculo e desenho e outra, especial, relativa á educação, compreendendo trabalhos manuais, jogos, exercícios physicos correctivos e os exercícios de orthopedia mental, recomendados por Binet (MINAS GERAIS, 1928, p.1244).

Os exercícios deveriam passar dos mais simples aos mais complexos. Os exercícios de ortopedia mental utilizados pelas professoras nas classes especiais foram retirados, principalmente, da obra de Binet e Descoeudres. Outros exercícios foram baseados na obra de Montessori e outros foram introduzidos pela própria Antipoff. Os exercícios trabalhavam, por exemplo, a memorização, a inteligência, a atenção. Tinham que ser agradáveis e estimulantes para as crianças, curtos de duração, para que elas nâo se cansassem e gradativos em sua aplicação, ou seja, dos mais fáceis aos mais difíceis, para que as crianças se sentissem estimuladas com suas vitórias e desejassem continuar. Exemplo de exercício de ortopedia mental:

Exercício de Observação - Memória Visual Exercício: Observar uma gravura durante 30" para depois enumerar seus elementos. Ou melhor, interpretá-la. Observaçâo: Apresentei-lhes a figura e deixei que observassem bem. Findo o tempo, as crianças começaram a fazer a descrição e enumeração da mesma. Houve, aqui muita desordem, todos queriam falar ao mesmo tempo; dei um sinal na campainha para fazerem silêncio e comecei fazendo perguntas a um e outro, separadamente, procurando fazer com que ouvissem a descrição do colega interrogado. Quase todos gostaram muito e responderam direitinho às perguntas que lhe foram feitas, quanto à 
descrição e enumeração. Mas, quanto à cor, interpretação da cena que representa a gravura e posição dos animais, muitos erraram (REZENDE, 1933, p. 74).

Antipoff descreve outros exercícios de ortopedia mental, cada qual com o objetivo de treinar uma das funções superiores, como a atenção, a discriminação visual e auditiva, etc. (ANTIPOFF, 1930/1992b). Os exercícios deveriam passar dos mais simples aos mais complexos. Também eram realizados jogos de execução de ordens verbais, como o jogo de obediência (baixar-se, ficar numa perna só, pular, etc.). A coordenação motora deveria ser trabalhada utilizando, inclusive, o que cada sala teria de recursos, como as tábuas do piso, que alinhadas, serviriam como um caminho. Além disso, a ginástica, o canto, os trabalhos manuais e a jardinagem eram atividades estimuladas. Aulas diária de no mínimo de 30 minutos eram dadas. As aulas de canto e de trabalhos manuais (colagens, recortes de figuras, desenhos, etc.) também eram diárias. As aulas de jardinagem dependiam da escola ter o local apropriado para a atividade ou náo.

A ginástica objetivava o desenvolvimento físico, ao mesmo tempo que educar a atenção, a observação, a memória. O ritmo era utilizado como meio coordenador dos movimentos. Os exercícios eram de marcha, de cadência, de palmas, correr passando por sinais feitos com giz no chão, etc. Evitavam-se jogos competitivos para não acirrar a agressividade das crianças. Os exercícios de imitação deveriam começar com a ginástica sueca denominada de calistenia (exercícios físicos que trabalham todos os membros, superiores e inferiores do corpo). $\mathrm{O}$ exercício de "estátua" deveria ser utilizado, pois treina a atenção.

O canto era utilizado como relaxamento. O conhecimento do ritmo, com o acompanhamento de palmas e gestos, ao lado da educação do ouvido, visava melhorar a sociabilidade, a cooperação, a obediência. Algumas classes organizaram uma banda de música, as próprias crianças fabricavam os instrumentos.

Os desenhos e trabalhos manuais procuravam contribuir para o desenvolvimento viso-motor da criança. Os desenhos eram livres ou croquis sobre as excursóes, por exemplo. Os trabalhos manuais eram realizados na maior parte das aulas possível, diariamente. As crianças faziam tapetes, limpa-pés de tampinhas de garrafas, tapetes de crochet, tecelagem com restos de lá, e muitos outros. Foi introduzida também a confecção de jogos, como o dominó.

A jardinagem era realizada no terreno da escola, quando possível, ou plantava-se em vasos que ficavam próximos das salas de aula. A Sociedade Pestalozzi forneceu a maior parte do material utilizado nas classes. Outros exercícios de ortopedia mental são descritos na obra de Antipoff. Todos objetivando o treinamento dos sentidos com o objetivo de reorganizá-los para que as crianças pudessem utilizá-los de forma mais eficiente.

Assim, sem ter o direito de pensar que a educação pode criar ou mesmo aumentar o potencial das faculdades inatas das crianças, temos a convicção de que o exercício racional e sistemático pode organizá-las pela maneira mais profícua, criando na criança os hábitos mais eficazes para fazê-las funcionar e aumentar-lhes a produção útil (ANTIPOFF, 1930/1992b, p. 68).

\section{Classes especiais no Instituto Pestalozzi}

As classes especiais do Instituto seriam, de acordo com o projeto, destinadas às crianças "educáveis" (SOCIEDADE PESTALOZZI,1934, p.11). A matrícula seria realizada a partir 
da demanda do Consultório Médico Pedagógico e se o Consultório solicitasse, o Instituto poderia matricular crianças mais debilitadas. As primeiras classes seriam para crianças de sete a 10 anos, de ambos os sexos, com método pedagógico semelhante aos do Jardim de Infância, além dos métodos da educação especial. E ainda, duas classes para crianças de 10 a 14 anos, diferenciadas por sexo. Nessas classes, seria dada atenção especial à formação dos alunos, com a utilização de métodos especiais, como trabalhos manuais, jardinagem, tecelagem, cartonagem, marcenaria, sapataria, serviços domésticos. Além disso, contaria com classes para crianças surdas e outra para casos em que se fizesse necessário um esclarecimento diagnóstico. Fora do horário escolar, as salas poderiam ser utilizadas para atendimento das crianças pelos especialistas.

As professoras dessas classes deveriam ser, preferencialmente, formadas pela Escola de Aperfeiçoamento, além de estagiárias que se especializariam na questão dos deficientes, a partir de estágio de seis meses nas classes especiais. Quanto aos métodos de ensino: “[...] serão inspirados nos sistemas educativos de Montessori, Decroly, Descoeudres, Sante de Sanctis, etc. e nos princípios da escola ativa moderna em geral, que se mostrou apropriada aos deficientes mentais" (SOCIEDADE PESTALOZZI, 1934, p.12).

O Instituto foi efetivamente criado através do decreto 11.908 de 5 de abril de 1935 , mas desde fevereiro de 1935, já funcionavam em suas dependências, três classes especiais. No final de março seriam abertas mais duas ou três classes. Assim, de acordo com Antipoff (1935/1944), no ano de 1935 haveriam duas classes para crianças “[...] entre 7 e 11 anos de ambos os sexos, retardadas, sem graves defeitos de caráter; uma classe para crianças da mesma idade, nervosas, psicastênicas, com inteligência relativamente normal" (ANTIPOFF, 1935/1944, p.17). E ainda, duas classes para alunos entre 12 e 14 anos que ficaram seis ou oito anos na escola, mas que não aprenderam suficientemente bem. Outra classe que já funcionava era a classe de responsabilidade de Esther Assumpção, formada por crianças "surdo-mudas".

A relação entre a Sociedade Pestalozzi e o governo de Minas Gerais foi legalizada através do decreto. Assim, a Sociedade Pestalozzi seria responsável pelo Instituto, mas o governo cederia pessoal administrativo e corpo docente. Uma parceria público-privado estabelecida em prol das crianças "excepcionais". A clientela que o Instituto Pestalozzi absorveu foi bem diversificada:

Para minorar a miséria moral em que se achavam, naquela época, os clientes do antigo ABRIGO DE MENORES, resolveu a diretoria matricular cerca de 50 desses em regime de semi-internato, entre seus primeiros alunos. Bastante inteligentes, porém filhos da rua, ofereciam, sem sua maioria, condutas anti-sociais de extrema agressividade, representando perigo muitas vezes para seus colegas e educadores. Com tal corpo discente, variando seu nível mental desde o estado de idiotia e imbecilidade, até graus de inteligência superior, dotados, alguns, de apreciáveis aptidōes especiais (mecânica, pintura, poesia, liderança, sociabilidade) o grupo de professoras encontrava sérios problemas em seu trabalho de iniciaçáo ao ensino especializado. Todas eram novatas nesse setor. Umas possuidoras, em sua maioria de diploma da famosa Escola de Aperfeiçoamento Pedagógico, criada por Francisco Campos em cumprimento de sua Reforma de Ensino do estado de Minas Gerais, em 1929 (ANTIPOFF,1965/ 2002, p.279).

Em 1935, o Instituto Pestalozzi possuía 74 alunos matriculados. Foram organizadas cinco classes: duas para débeis mentais mais ou menos profundos, uma para surdos-mudos e duas para meninos de maior idade, sem retardo mental, mas com atraso escolar ou com dificuldades de caráter social (ANTIPOFF, 1935/1944). Em 1936, o número de alunos chegou a 90 
alunos. Os meninos de Abrigo, que estavam sendo atendidos no Instituto Pestalozzi, chamavam a atenção pela diminuição de peso. Esse fato ocorreu porque, segundo Antipoff, eles continuavam recebendo a mesma alimentação no Abrigo, mas no Instituto sua vida era muito mais dinâmica, ao contrário do Abrigo, onde permaneciam numa imobilidade total. $\mathrm{O}$ aumento da alimentação era a preocupação da diretoria (ANTIPOFF, 1936/1944). Foi gasta uma grande soma de dinheiro no aparelhamento do Instituto, que deveria criar o meio necessário para a prática da Escola Ativa nas classes:

Possuem elas aparelhamento mínimo necessário para diferenciar a pedagogia de cada tipo de crianças: o material didático, de Montessori, Asen, Decroly, os jogos educativos comprados ou fabricados no próprio Instituto, permitem, com os débeis mentais, a educação especial intelectual, sensorial e motora (esta última também favorecida pela possibilidade de se utilizar do parque de recreio "Olegário Maciel, vizinho ao Instituto" (ANTIPOFF, 1936/1944, p. 34).

Para as crianças maiores, foram adquiridas ferramentas para trabalhos de sapataria, carpintaria e trabalhos comuns. A horta foi acrescida de um terreno de $880 \mathrm{~m} 2$, ampliando as suas possibilidades educativas. As classes ficavam a cargo de quatro professoras, três delas formadas pela Escola de Aperfeiçoamento e pela diretora, Esther Assumpção, além do auxílio de um mestre sapateiro e outro que cuidava da horta.

A instituição não tinha serventes, os meninos e as professoras cuidavam da limpeza da casa. Os exercícios escolares, as leituras recreativas, os trabalhos domésticos, as oficinas, as reunióes com a diretora, as excursóes, todas atividades eram valorizadas: "[...] toda e qualquer atividade da criança, por mais banal e humilde que seja, considera-se no Instituto com a mesma seriedade e utiliza-se invariavelmente para fins educativos" (ANTIPOFF, 1936/1944, p. 34).

A grande preocupação e finalidade do Instituto era adaptar as crianças às necessidades da vida econômica e social, desenvolvendo nelas as aptidóes necessárias para que tivessem uma vida menos parasitária e mais digna. Assim, as crianças cujo nível mental se encontra entre quatro e sete anos deveriam ser estimuladas a encontrar um trabalho repetitivo, que para a maior parte das pessoas é maçante, mas que para essas crianças é ideal, pois elas não se cansam de fazer a mesma coisa. Os débeis com limite superior a 12 anos podiam ser estimulados a um trabalho com maior responsabilidade, mas não esquecendo que falta a essas pessoas a capacidade de intervir de uma maneira individual e adequada a uma situação nova. A dignidade estava ligada assim, a possibilidade de que essas crianças tivessem uma vida produtiva, quando adultas. Seria necessário, de acordo com Antipoff, aproveitar as aptidóes especiais de cada um.

Em 1937, havia 137 crianças matriculadas no Instituto Pestalozzi (ANTIPOFF, 1937/1944). As classes tinham um duplo objetivo, de acordo com Antipoff: educar os alunos e incentivar a ciência pedagógica. As professoras, imbuídas do espírito científico, procuravam "[...] descobrir os mistérios de uma personalidade mal formada ou atrapalhada e aplicar os meios próprios para endireitá-la e ajustá-la às exigências de uma vida social mais elevada” (ANTIPOFF,1937/1944, p.53).

Em 1938, o Instituto Pestalozzi já contava com 150 alunos. Uma classe para crianças surdas, seis classes para crianças de idade mental entre dois anos e 13 anos e idade real entre sete e 16 anos. Embora a proposta inicial fosse de receber somente crianças educáveis, desde o iní- 
cio o Instituto recebeu crianças de "nível inferior", os "não educáveis", segundo a classificação de Heuyer (ANTIPOFF, 1938/1944, p. 76).

Heuyer adota na sua conceituação, unicamente o critério social, partindo da noção de que "normal é o indivíduo capaz de adaptar-se socialmente". O índice dessa adaptabilidade é subordinado à duas condiçôes: a não nocividade e a capacidade de bastar-se a si próprio, sem precisar ser assistido (TEIXEIRA, 1932, p. 27).

Em 1939, o Instituto recebeu 40 crianças débeis mentais profundas, não ficando claro a procedência dessas crianças (ANTIPOFF, 1938/1944). Segundo ela, o problema dos débeis profundos continuava sem solução em Minas Gerais. Mesmo sem uma estrutura adequada para receber essas crianças, Antipoff não se absteve. Abriu as portas, assim como fez para uma outra população que não era a clientela do Instituto, para as crianças do Abrigo Afonso de Moraes.

Portanto, o Instituto Pestalozzi estabeleceu-se como uma escola especial, no modelo de externato, mas desde o início, com essas particularidades. Não constava nos estatutos a oferta de vagas para débeis profundos, mas na falta de um local adequado, essas crianças foram recebidas, assim como as crianças abrigadas. $\mathrm{O}$ modelo de educação foi baseado na Escola Ativa e oficinas foram organizadas, como a de sapataria, a de encadernação e a de jardinagem. Como o Consultório Médico Pedagógico anexou-se ao Instituto, tratamento e educação eram ofertados pela instituição.

\section{CONSIDERAÇÓES FINAIS}

Como vimos, a classe especial não foi uma prerrogativa mineira. Seu estabelecimento já estava previsto no Regulamento do Ensino Primário de 1927, quando Antipoff chega a Belo Horizonte. Mas Antipoff era a favor das classes especiais. Claparède já havia trabalhado em Genebra com esse modelo de ensino era o que parecia ser o mais apropriado. Numa época em que poucas crianças tinham acesso à educação, mesmo com a obrigatoriedade do ensino, a chegada das crianças anormais à escola e sua permanência nesse ambiente estavam constantemente ameaçadas. Salas com menos alunos, professores capacitados, aulas diferenciadas, ensino individualizado: esse era o ideal de classe especial que Antipoff pretendia estabelecer. Antipoff acreditava que esse ensino diferenciado poderia promover o desenvolvimento das crianças anormais. Nesse sentido, a classificação das crianças deveria servir para homogeneizar as classes e promover o ensino individualizado.

A entrada da criança na classe especial se dava através da realização dos testes. No entanto, Antipoff considerava importante relativizar seu uso. Seus resultados não eram uma sentença na vida da criança. A classificação psicológica é comparada por Antipoff a classificação das plantas, na botânica. Assim é que um espécime da botânica, uma vez reconhecido e levado ao herbário, permanecerá imóvel no mesmo lugar. Quanto a criança, mesmo que o critério permaneça o mesmo, “[...] o espécime, que é o indivíduo, pode mudar e evolver a tal ponto que o escaninho onde há tempos foi colocado, no fim de certo prazo, le será demasiadamente estreito ou largo" (ANTIPOFF, 1935/2002, p.214). Evolver significa desenvolver-se gradualmente, evolucionar, evoluir. A palavra parece ter sido escolhida a dedo. A criança na visão de 
Antipoff, evolui. Crianças das Classes D poderiam alcançar a Classe A, através de seus méritos e desenvolvimento, sem necessidade de esperar o ano todo para ser transferida.

Assim, a inteligência não podia ser limitada ao terreno das aptidóes naturais, mas seria um produto complexo, que envolveria o ambiente, os estímulos que a criança teve e o acesso aos bens culturais. Helena Antipoff amplia o conceito de inteligência. O que Helena Antipoff quis dizer é que, crianças criadas num meio desfavorável, sem acesso aos bens culturais, sem os estímulos, apresentarão déficits nos testes, embora essas crianças tenham a inteligência natural, ou seja, não sejam deficientes mentais, simplesmente essas crianças não tiveram contato com os códigos, os instrumentos que lhes permitissem apresentar um bom desempenho, seja nos testes, seja no ambiente escolar, um ambiente que tem códigos próprios de conduta.

No entanto, as classes especiais seriam necessárias para acolher crianças com déficits verdadeiros. As classes especiais foram concebidas, como demonstrado acima, a partir da possibilidade de ofertar um ensino individualizado. $\mathrm{O}$ trabalho que deveria ser realizado partia do ideário da escola nova. Os métodos da escola ativa priorizando a "educação sob medida", procuravam estimular a criança, partindo das funçóes mentais mais básicas. Esse ensino pretendia que a criança avançasse, mas respeitando os limites do aluno.

Antes do estabelecimento das classes especiais, as crianças consideradas anormais eram internadas em asilos psiquiátricos ou mantidas enclausuradas em casa. As classes especiais mineiras foram uma proposta inovadora na época, ao reconhecer e respeitar as diferenças individuais, ao propor uma metodologia diferenciada e acima de tudo, ao acreditar na educabilidade de crianças consideradas até então, irrecuperáveis.

\section{REFERÊNCIAS}

ANTIPOFF, H. A homogeneização das classes escolares (1930). In: CDPHA - Centro de Documentação e Pesquisa Helena Antipoff (Org.). Coletânea das Obras Escritas de Helena Antipoff, Volume 3: Educação do Excepcional. Belo Horizonte: Imprensa Oficial, 1992b. p.31-35.

ANTIPOFF, H. Plano para organização das classes do $1^{\circ}$ ano (1930). In: CDPHA - Centro de Documentação e Pesquisa Helena Antipoff (Org.). Coletânea das Obras Escritas de Helena Antipoff, Volume 3: Educação do Excepcional. Belo Horizonte: Imprensa Oficial, 1992b. p.39-44.

ANTIPOFF, H. Classes especiais "D” e "E" - Modo de formulá-las (1930). In: CDPHA - Centro de Documentação e Pesquisa Helena Antipoff (Org.). Coletânea das Obras Escritas de Helena Antipoff, Volume 3: Educação do Excepcional. Belo Horizonte: Imprensa Oficial, 1992b. p.47-48.

ANTIPOFF, H. Seleção dos professores para cada tipo de classes (1930). In: CDPHA - Centro de Documentação e Pesquisa Helena Antipoff (Org.). Coletânea das Obras Escritas de Helena Antipoff, Volume 3: Educação do Excepcional. Belo Horizonte: Imprensa Oficial, 1992b. p.53-54.

ANTIPOFF, H. Progressos escolares de cada tipo de classe e meios de controla-las (1930). In: CDPHA - Centro de Documentação e Pesquisa Helena Antipoff (Org.). Coletânea das Obras Escritas de Helena Antipoff, Volume 3: Educação do Excepcional. Belo Horizonte: Imprensa Oficial, 1992b. p.55-60.

ANTIPOFF, H. Da ortopedia mental (1930). In: CDPHA - Centro de Documentação e Pesquisa Helena Antipoff (Org.). Coletânea das Obras Escritas de Helena Antipoff, Volume 3: Educação do Excepcional. Belo Horizonte: Imprensa Oficial, 1992b. p.67-74. 
ANTIPOFF, H. O desenvolvimento mental das crianças de Belo Horizonte (1931). In: CAMPOS, R.H.F. (Org.). Helena Antipoff: textos escolhidos. São Paulo: Casa do Psicólogo Livraria e Editora Ltda; Brasília, DF: Conselho Federal de Psicologia, 2002. p.83-125.

ANTIPOFF, H. A pedagogia nas classes especiais (C. D). Revista do Ensino - Órgão oficial da inspetoria geral do ensino, v. 6, n. 56,57,58, p. 24-39, 1931.

ANTIPOFF, H. Organização das classes nos grupos escolares de Belo Horizonte (1932). In: CDPHA - Centro de Documentação e Pesquisa Helena Antipoff (Org). Coletânea das Obras Escritas de Helena Antipoff, Volume 1: Psicologia Experimental. Belo Horizonte: Imprensa Oficial, 1992a. p.131-150.

ANTIPOFF, H. Ortopedia mental nas classes especiais (1934). In: CDPHA - Centro de Documentação e Pesquisa Helena Antipoff (Org). Coletânea das Obras Escritas de Helena Antipoff, Volume 3: Educação do Excepcional. Belo Horizonte: Imprensa Oficial, 1992b. p.27-29.

ANTIPOFF, H. Relatório da Primeira Diretoria da Sociedade Pestalozzi (1932-1935) apresentado à assembleia geral no dia 17 de março de 1935, pela sua presidente, professora Helena Antipoff. (1935) Coleção do Departamento Nacional da Criança. Rio de Janeiro: Imprensa Nacional, 1944.

ANTIPOFF, H. Assembleia Geral de 1936 (1936). Coleção do Departamento Nacional da Criança. Rio de Janeiro: Imprensa Nacional, 1944.

ANTIPOFF, H. Breve relatório da Sociedade Pestalozzi para o ano de 1936 e o primeiro trimestre de 1937 (1937). Coleção do Departamento Nacional da Criança. Rio de Janeiro: Imprensa Nacional, 1944.

ANTIPOFF, H. Relatório Geral do Exercício da Sociedade Pestalozzi em 1938 (1938). Coleção do Departamento Nacional da Criança. Rio de Janeiro: Imprensa Nacional, 1944.

ANTIPOFF, H. O De lustro em lustro: os jubileus das três instituiçóes para excepcionais (1965). In: Campos, R.H.F. (Org.). Helena Antipoff: textos escolhidos. São Paulo: Casa do Psicólogo Livraria e Editora Ltda; Brasília: Conselho Federal de Psicologia, 2002. p. 279-284.

ASSUMPÇÃO, E. Nossa experiência com o ensino e a educação dos surdos-mudos. Boletim da Secretaria da Educação e Saúde Pública de Minas Gerais, Publicação a cargo da Sociedade Pestalozzi - A Infância Excepcional (sub-normaes e desamparados), n.16, p. 67-75, 1934.

CAMPOS, R.H.F., LOURENÇO, E., ANTONINI, I.G. Introdução - Helena Antipoff e a psicologia no Brasil. In: CAMPOS, R.H.F. (Org.). Helena Antipoff: textos escolhidos. São Paulo: Casa do Psicólogo Livraria e Editora Ltda; Brasília, DF: Conselho Federal de Psicologia, 2002. p.12-36

CAMPOS, R. H. F. Helena Antipoff (1892-1974) e a perspectiva sociocultural em psicologia e educação. Tese (Concurso para Professor Titular) - Faculdade de Educação, Universidade Federal de Minas Gerais, Belo Horizonte, MG, Brasil, 2010.

CLEOPAZZO, C. Alice Descoeudres: un humanisme vivant. Etude de la carrière d'une psycho-pédagogue. Mémoire (License en Sciences de l'Education), Université de Genève, 1996.

FAZZI, E. O Laboratório de psicologia da escola de aperfeiçoamento de Belo Horizonte (1929-1946). Dissertação (Mestrado em Educação) - Faculdade de Educação, Universidade Federal de Minas Gerais, Belo Horizonte, MG, Brasil, 2005.

LOPES, E. M. T.; GALVÃO, A. M.O. História da Educação. 2.ed. Rio de Janeiro: DP\&A Editora, 2005. MASSIMI, M. Novas questóes temáticas e desdobramentos metodológicos na história dos saberes psicológicos. Temas em Psicologia, Ribeirão Preto, v.17, n.1, p.15-20, 2009. 
MINAS GERAIS. Leis e Decretos do Estado de Minas Gerais (1927). Vol. I, II, III. Belo Horizonte: Imprensa Oficial, 1928. Biblioteca Luís Bessa, Belo Horizonte, MG.

SAMARA, E.M.; TUPY, I. S. S. T. História \& documento e metodologia de pesquisa. Belo Horizonte: Autêntica Editora, 2007.

REZENDE, N. As atividades da Sociedade Pestalozzi. Boletim da Secretaria da Educação e Saúde Pública de Minas Gerais, n.12, Publicação a cargo da Sociedade Pestalozzi - A Infância Excepcional (sub-normais), p. 71-75, 1933.

REZENDE, N. Orientação do ensino nas classes especiaes dos grupos escolares de Belo Horizonte, em 1933. Boletim da Secretaria da Educação e Saúde Pública de Minas Gerais, Publicação a cargo da Sociedade Pestalozzi - A Infância Excepcional (sub-normaes e desamparados), n.16, p.55-66, 1934.

RUCHAT, M. (Ed.) Édouard Claparède-Hélène Antipoff-Correspondance (1914-1940). Firenze: Leo Olschiki Editore, 2010.

SOCIEDADE PESTALOZZI. Assistência a menores em Minas Gerais. Boletim da Secretaria da Educação e Saúde Pública de Minas Gerais, Publicação a cargo da Sociedade Pestalozzi - A Infância Excepcional (sub-normaes), n.12, p.47-51, 1933.

SOCIEDADE PESTALOZZI. Projecto do Instituto Pestalozzi de Bello Horizonte. Boletim da Secretaria da Educação e Saúde Pública de Minas Gerais, Publicação a cargo da Sociedade Pestalozzi - A Infância Excepcional (sub-normaes e desamparados), n.16, p.09 -15, 1934.

Recebido em: 04/11/2014

Reformulado em: 13/07/2015

Aprovado em: 14/07/2015 